https://doi.org/10.15407/ujpe64.5.425

N.V. BONDAR, ${ }^{1}$ M.S. BRODYN,${ }^{1}$ O.V. TVERDOKHLIBOVA, ${ }^{1}$ N.A. MATVEEVSKAYA,${ }^{2}$ T.G. BEYNIK ${ }^{2}$

${ }^{1}$ Institute of Physics, Nat. Acad. of Sci. of Ukraine

(46, Prosp. Nauky, Kyiv 03028, Ukraine)

2 Institute for Single Crystals, National Acad. of Sci. of Ukraine

(60, Nauka Ave., Kharkiv 61001, Ukraine)

\title{
INFLUENCE OF A CAPPING LIGAND \\ ON THE BAND GAP AND EXCITONIC LEVELS IN COLLOIDAL SOLUTIONS AND FILMS OF ZnSe QUANTUM DOTS
}

\section{Introduction}

Organic ligands, when being placed onto the surface of semiconductor quantum dots (QDs), play an important role and, depending on such parameters as their chemical origin, the length of molecular chains, the forces bonding them to the QD surface, and their concentration, can perform various functions [1]. The simplest of those functions is the passivation of dangling bonds of superficial atoms. This function prevents the formation of defect states in QDs and enhances the quantum yield of the latter. The stabilization of QDs with organic ligands also prevents their aggregation in solutions and allows the formation of ordered and densely packed 3D or 2D arrays (superlattices or films) to be carried out. However, if the molecular chain length of ligands is considerable e.g., as in oleic acids (about $2.0 \mathrm{~nm}$ ) - then, according to their electrical properties, such structures can become insulators. Therefore, a necessity often arises to

(C) N.V. BONDAR, M.S. BRODYN,

O.V. TVERDOKHLIBOVA, N.A. MATVEEVSKAYA,

T.G. BEYNIK, 2019

ISSN 2071-0194. Ukr. J. Phys. 2019. Vol. 64, No. 5 substitute long organic ligands by shorter ones which chain lengths are not longer than $1 \mathrm{~nm} \mathrm{[1-3].}$

The study of the processes of QD surface capping showed that the optical and electrical properties of the treated QDs, as well as their arrays, depend to a large extent on the type of organic ligands, their chemical origin, the anchor group, and the number of ligands on the QDs surface [1]. It was found that, depending on the chemical nature of the ligand anchor group and the ligand amount, the optical gap of the complex QD + ligand can either decrease or increase. In the former case, the gap reduction makes it possible to "pull out" an electron or a hole from the QD and to prevent their recombination. In the latter case, on the contrary, owing to the compression of the exciton wave function, it becomes possible to increase the energy of $e-h$ pairs [1-6]. Along with the quantum confinement effect, which nowadays is the most studied property of semiconductor QDs, this circumstance allows their energy to be controlled in a wide interval of their sizes, and the wave function of charge carriers in QDs to be governed without changing the actual sizes of QDs. 
In the prevailing number of cases, typical organic ligands of colloidal QDs are ligands with hydroxyl, thiol, or carboxyl anchor groups or with an amino group. Ligands possess different affinities with respect to superficial QD atoms, which depend on the type of the bond that they mutually form between them. For example, the highest affinities with respect to CdSe and CdS QDs belong to thiols (thiolates), which form a covalent bond with the superficial Cd atoms [4-6]. The treatment of the surface of CdS and CdSe QDs with dithiocarbamates reduces the forbidden gap in those QDs by about 970 and $220 \mathrm{meV}$, respectively, by means of the hole delocalization at a ligand molecular orbital. This is the so-called bathochromic effect, which enables holes or electrons to be "pulled out" from QDs, preventing their recombination and not changing the QD chemical composition $[4,5]$. The efficiency of those processes in the colloidal solutions of hole-acceptor complexes depends on the position of HOMO-LUMO ligand levels with respect to the valence and conduction bands in the QDs and with respect to the vacuum level. If a QD-ligand complex belongs to type-II, then holes rapidly transit from the QD into the ligand shell, as it takes place, e.g., in the CdSe QDphenyldithiocarbamate (PTC) complex [7-12]. Nowadays, those processes are mainly studied on the basis of QDs of CdX and PbX (X = S, Se, Te) chalcogenides $[1,4-6]$. At the same time, $\mathrm{ZnX}$ QDs remain little researched owing to a complicated procedure of their synthesis and their rather wide optical gap.

The reverse action of organic ligands has also been studied rather poorly, since it is believed to be less important from the practical viewpoint and lead to the additional localization of excitons in QDs. As a result of the reverse ligand action and an increase of the optical gap in QDs, there arises a hypsochromic shift, so that the bands in the absorption or transmission spectra become shifted toward short waves. This phenomenon was observed in CdSe and CdS QD films treated with ionic cyanides [13-15]. The authors of the cited works came to the conclusion that an increase of the optical gap in CdSe QDs can be a result of the electrostatic compression of the exciton wave function due to the interaction of cyanides (the negative $\mathrm{CN}^{-1}$ fragment) with the superficial $\mathrm{Cd}$ and Se atoms.

The short-wave shift of the absorption band was also observed in CdSe QDs, when their surface was treated with amines. However, this shift was explained by changes in either the size or chemical structure of QDs, and today there is no consensus concerning the origin of this phenomenon.

Other issues that have been little studied till today are the creation of films on the basis of colloidal solutions with treated QDs and how the optical spectra of the charge carrier energy transform at the transition from colloidal solutions to solid films. The importance of such studies consists in that it is QD films that form a basis for the creation of optoelectronic devices. However, once again, such studies are not comprehensive at present.

In this work, the optical spectra of colloidal solutions of ZnSe QDs, both pure and stabilized with 1-thioglycerol (hereafter, ZnSe-TG QDs), as well as films on their basis, have been analyzed. The chosen thiol-based ligand is well known, and it is often used to stabilize QDs, because, at one end of its molecular chain, there is a thiol -SH group with an affinity to the ZnSe QD atoms. We have shown for the first time that the interaction of the thiol $-\mathrm{SH}$ group of the stabilizer with the superficial atoms of ZnSe QDs, in combination with the quantum confinement effect, significantly increases both the exciton energy in the QDs and the QD optical gap. The account of this contribution gives rise to good agreement between experimental and theoretical results.

\section{Experimental Part}

Colloidal solutions and films of ZnSe QDs on quartz substrates were fabricated making use of Sigma-Aldrich materials without their additional purification. Quantum dots of ZnSe were synthesized in the exchange reaction between NaHSe and $\mathrm{Zn}\left(\mathrm{NO}_{3}\right)_{2} \cdot 6 \mathrm{H}_{2} \mathrm{O}$ in the presence of thioglycol $\mathrm{C}_{3} \mathrm{H}_{8} \mathrm{O}_{2} \mathrm{~S}$ (TG) in the aqueous solution [16]. Colloidal $\mathrm{QD}$ solutions were obtained by dissolving $\mathrm{Zn}\left(\mathrm{NO}_{3}\right)_{2} \cdot 6 \mathrm{H}_{2} \mathrm{O}$ in deionized water with the addition of $\mathrm{TG}$ at $\mathrm{pH}=11$; then $\mathrm{N}_{2}$ was passed through the solution for $30 \mathrm{~min}$ at room temperature; afterward, $5 \mathrm{ml}$ of NaHSe was added, and the mixture was stirred for $2 \mathrm{~h}$ in the $\mathrm{N}_{2}$ atmosphere at the temperature $T \approx 100{ }^{\circ} \mathrm{C}$.

Two series of ZnSe QDs specimens with the molar ratios $\mathrm{Zn}^{2+}: \mathrm{Se}^{2-}=2: 1$ (specimens $\mathrm{S} 21$ ) and $1: 1$ (specimens S11) were synthesized. In order to obtain ZnSe-TG QDs, the masses $n(\mathrm{TG})=2.5,5,7$, and

ISSN 2071-0194. Ukr. J. Phys. 2019. Vol. 64, No. 5 
$10 \mathrm{mmol}$ of TG were added to the solution in the case of S21 specimens, and the TG masses $n(\mathrm{TG})=3.5$, 5 , and $10 \mathrm{mmol}$ in the case of S11 ones. With the addition of $\mathrm{TG}$, the solution changed its color from transparent to orange at $n \approx 5 \mathrm{mmol}$ in the former case, and at $n \approx 10 \mathrm{mmol}$ in the latter one. The concentration of ZnSe QDs in both specimens (S21 and S11) was the same, $n_{0}(\mathrm{QD})=8.3 \mathrm{mmol} / \mathrm{l}$.

The hydrodynamic radius of the $\mathrm{ZnSe}$ QD-TG complex was obtained by analyzing the dynamic light scattering (DLS) on a Zetasizer Nano ZS installation. According to the data obtained and taking the TG molecule length $\ell \approx 0.75 \mathrm{~nm}$ into account, the average radius of $\mathrm{ZnSe} \mathrm{QDs}$ was determined to equal $R_{0} \approx 2.9 \pm 0.2 \mathrm{~nm}$. Owing to the quantum confinement effect, the energy of excitons in a QD with this radius comprises only about $10 \%$ of the energy gap width in the ZnSe bulk, $E_{g 0}$, which can be estimated in the framework of the model "a particle in a spherical potential well" with an infinite barrier height or with a height that is comparable with $E_{g 0}(\mathrm{TG})$ (see below). The DLS was also used to monitor the dimensions of the ZnSe QD-TG complex after every addition of the stabilizer.

Thin films on the basis of S21 specimens with $n(\mathrm{TG})=2.5,5,7$, and $10 \mathrm{mmol}$ (F2.5, F5, F7, and F10, respectively) were deposited onto quartz substrates using the spin-coating method. The ratio between the number of TG molecules and the number of ZnSe QDs in the solutions used for fabricating those films can be roughly estimated as $0.28 \times 10^{2}$, $0.55 \times 10^{2}, 0.77 \times 10^{2}$, and $1.1 \times 10^{2}$, respectively. However, it was quite difficult to evaluate the number of TG molecules that became directly bound to the superficial atoms in ZnSe QDs. Currently, this procedure is one of the most complicated. Even the application of such methods as ${ }^{1} \mathrm{H}$ nuclear magnetic resonance (NMR) allows the number of the QD superficial atoms to be determined only approximately.

The morphology and the structure of the films were studied on a scanning electron microscope JSM-6490 LV (JEOL) equipped with an attachment for chemical analysis Oxford Instruments EDS INCAxact. The stationary absorption spectra of the solutions of pure TG and with the ZnSe-TG QDs in standard 1-cm quartz cuvettes were registered on a SHIMADZU UV mini-1240 spectrometer, and the absorption spectra of ZnSe-TG QD solid films on a SHIMADZU-2450 UV-vis-NIR spectrometer. A spectrometer PERKIN-
ELMER LS-55 was used to register photoluminescence spectra.

\section{Results Obtained and Their Discussion}

\subsection{Superficial contribution \\ to the $1 S$ exciton transition energy in the optical spectra of ZnSe $Q D$ colloidal solutions and films}

Below, we will demonstrate and qualitatively substantiate the emergence of the hypsochromic effect in TG-stabilized ZnSe QDs, i.e. the reverse ligand action on the optical gap magnitude in QDs. Unlike the intensively studied bathochromic effect [1], the hypochromic one, as far as we know, was mentioned only in two works dealing with CdSe QDs, whose surface was treated with cyanides (the CN cyanogroup) [13-15]. A possibility for this effect to exist in ZnSe QDs treated with ligands with the thiol -SH group was theoretically shown in work [17]. In the mentioned works, it was noted that the reverse ligand action is electrostatic by its origin and, in general, is similar to the polarization effect detected earlier in II-VI semiconductor QDs synthesized in borosilicate glass $[18,19]$. The mismatch of dielectric permittivities in the QDs and glass gives rise to the polarization of the interface between them and the appearance of a polarization potential and an image charge that affect the motion of excitons in the QDs by increasing their energy. The authors of work [17], in the framework of the density functional theory, showed that the action of the thiol - $\mathrm{SH}$ group on the superficial metal atoms in ZnSe QDs can also bring about a similar effect. As a result of the chemisorption, the passivating $\mathrm{H}$ atom of the $-\mathrm{SH}$ group binds to the $\mathrm{Zn}$ atom, borrows some of its charge, and localizes it at its own site. When an $\mathrm{H}$ atom is bound to a Se one, the charge becomes accumulated near the middle point between those atoms. In the free state, thiols cannot join to the superficial atoms in $\mathrm{ZnSe}$ QDs, and, therefore, they dehydrogenate, by releasing the $\mathrm{H}$ atom. As a result, the bound state becomes a thiolate. In this case, the binding energy strongly increases, as the $\mathrm{QD}$ radius diminishes [20-23]. The charge accumulated at the ZnSe QD surface forms a potential that increases the exciton energy by electrostatically compressing the exciton wave function, so that there arises a short-wave shift of the $1 S$ transition energy in the TG-stabilized ZnSe QD. It should 


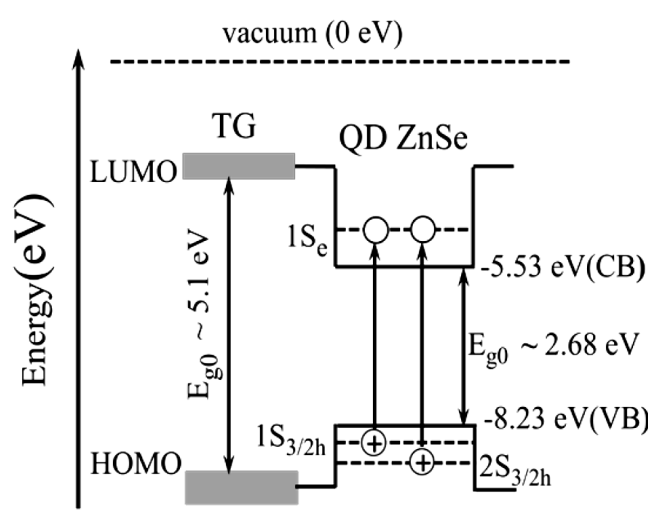

Fig. 1. Energy diagram of the ZnSe QD-TG complex

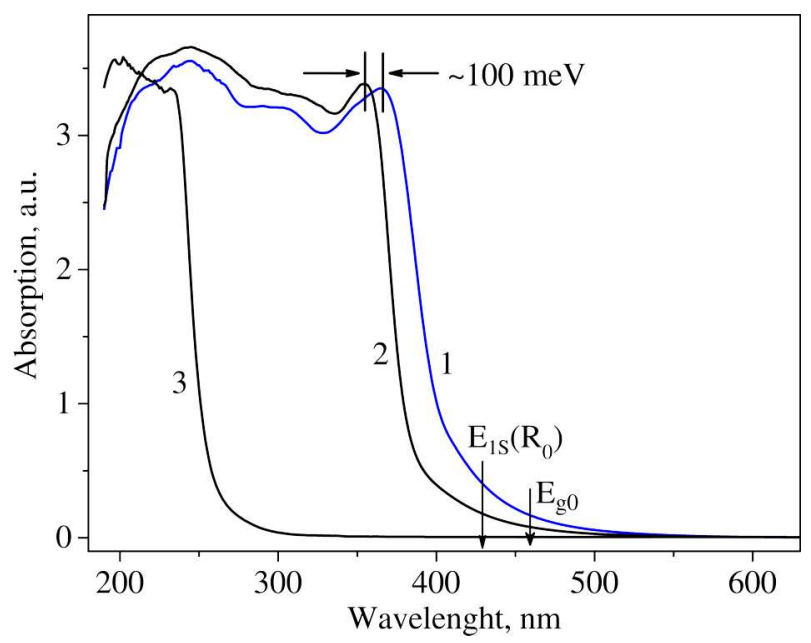

Fig. 2. Absorption spectra of samples S11 (1) and S21 (2) with $n_{0}(\mathrm{TG})=10 \mathrm{mmol} / \mathrm{l}$, and pure TG (3). Arrows mark the calculated energy of the exciton $1 S$ transition in the ZnSe $\mathrm{QD}, E_{1 s}$, and the energy gap width in $\mathrm{ZnSe}, E_{g 0} \approx 2.68 \mathrm{eV}$ $(\lambda \approx 462 \mathrm{~nm})$

be noted that this effect of TG on the charge carrier energy in ZnSe QDs may probably be selective, i.e. it may not be observed in other systems.

At first, let us consider the energy diagram of the ZnSe QDs-TG complex and estimate the exciton energy making allowance for the quantum confinement effect. Figure 1 demonstrates the energy diagram of the ZnSe-TG QD belonging to type-I, when the wave functions of the $e-h$ pairs are localized in the QD. The figure also demonstrates the positions of the conduction $(\mathrm{CB})$ and valence $(\mathrm{VB})$ bands in the bulk $\mathrm{ZnSe}$ reckoned from to the vacuum level, the notations $1 S$ and $2 S$ are used to indicate the quan- tum energy levels of the electrons and holes in the QDs, and the notations HOMO and LUMO marks the TG levels. Note that the type of an energy diagram (type-I or type-II) is determined by the positions of the HOMO and LUMO levels of TG, both with respect to the vacuum level and to the $\mathrm{CB}$ and VB in ZnSe. Although the TG gap is rather substantial, $E_{g 0}(\mathrm{TG}) \approx 5.1 \mathrm{eV}[22,23]$, it is the absolute positions of the HOMO and LUMO levels that determine the energy diagram type of the complex.

We found that capping the QD surface with TG molecules does not reduce the optical gap of the ZnSe QD-TG complex, as is also evidenced by the positions of the absorption and photoluminescence bands in the examined specimens. This could happen, if the HOMO (LUMO) level of TG would be below (above) the $\mathrm{VB}(\mathrm{CB})$ level in $\mathrm{ZnSe}$. In this case, the exciton dissociation would have led to a capture of an electron or hole into the ligand shell and to a reduction of the QD optical gap, so that a long-wave shift of the absorption band in TG-stabilized ZnSe QDs with respect to the same band in pure QDs would have been observed. Since all that does not happen, we may assert that the energy diagram of the ZnSe-TG QD belongs to type-I. Therefore, we obtain a possibility to estimate the energy of the exciton $1 S$ transition, $E_{1 S}$, in a $\mathrm{ZnSe} \mathrm{QD}$ with the radius $R_{0}$ in the framework of the model "a particle in a spherical potential" $[18,19]$, if assuming the confinement potential barrier created by TG at the ZnSe QD surface to be infinitely high.

As a result, we obtain $E_{1 S}\left(R_{0}\right) \approx 2.9 \mathrm{eV}(\lambda \approx$ $\approx 427 \mathrm{~nm})$. The calculated value correlates well with its counterpart obtained in work $[22,23]$ for ZnSe QDs with $2 R_{0}=5.7 \pm 0.4 \mathrm{~nm}(\lambda \approx 423 \mathrm{~nm})$. The position of $E_{1 S}\left(R_{0}\right)$ is marked by an arrow in Fig. 2. It is shifted by $E_{q} \approx 220 \mathrm{meV}$ with respect to $E_{g 0}$ owing to the quantum confinement effect. If the role of TG molecules were only reduced to the stabilization of ZnSe QDs and the creation of a potential barrier for charge carriers, then the maximum in the absorption band of the ZnSe QD-TG complex would coincide with $E_{1 S}\left(R_{0}\right)$. However, as one can see from Fig. 2, this is not the case.

Figure 2 also exhibits the absorption bands of the colloidal solutions of S11 (curve 1) and S21 (curve 2) specimens and pure TG (curve 3). The shape of band 1 has several peculiarities. Its first peak (at about $365 \mathrm{~nm}$ ) is formed by exciton tran- 
sitions from the $1 S$ state, which is shifted toward the short-wave side by $E_{s} \approx 500 \mathrm{meV}$ with respect to $E_{1 S}\left(R_{0}\right)$. Band 1 has a peak (at about $300 \mathrm{~nm}$ ) formed by either $1 S_{e}-2 S_{h h}$ exciton transitions or $1 S_{e}-1 S_{l h}$ electron transitions onto the energy level of light holes $(l h)$. In the ultraviolet interval, this band has another peak (at about $250 \mathrm{~nm}$ ). It is generated by the absorption of TG molecules that are fixed at the ZnSe QD surface. This peak is shifted toward lower energies as compared with a similar peak in band 3 formed by pure TG molecules.

The position of the first peak in band 1 with respect to $E_{1 S}\left(R_{0}\right)$ could be explained by the presence of ZnSe QDs with smaller dimensions (and higher exciton energies), which could be generated in the course of growth, when TG was added. This is a typical situation where a certain amount of stabilizer is added during the process of QD growing [1]. However, as was said in Section 2, the dimensions of ZnSe QDs remained invariant, when TG was added in the course of QD growing, which was shown by monitoring them with the help of DLS. From whence, we may conclude that the shift of the $1 S$ exciton energy level by $E_{s}$ in $\mathrm{S} 11$ specimens is a result the TG reverse action, which induces the compression of the wave function of excitons in the QDs and increases their energy. The chemisorption of molecules on the QD surface decreases their HOMO-LUMO gap in comparison with pure TG molecules, which is the evidence of that the superficial contribution to the exciton energy is associated with the ligand action.

An important indicator of the reverse ligand action on the exciton energy in QDs is the ratio between the parameters $E_{q}$ and $E_{s}$, which is less than unity in our case. Earlier, we showed [16] that this ratio exceeds unity for the same ZnSe QD-TG complexes but with $R_{0} \approx 2.0 \mathrm{~nm}$ and fixed on quasispherical substrates. This variation of the ratio $E_{q} / E_{s}$ is a consequence of the different dependences of those parameters on the QD radius. At the qualitative level, it can be explained as follows. If the quantity $E_{q}$ depends on the QD size as $R_{0}^{-2}$, then the quantity $E_{s}$ is most likely to have a linear or superlinear dependence and, therefore, becomes larger than $E_{q}$ at a certain $R_{0}$-value.

Another evidence of the reverse TG action can be obtained by analyzing the position of band 2 in the absorption spectra of S21 specimens; this band is also depicted in Fig. 2. Recall that the QDs in
S21 specimens are characterized by the molar ratio $\mathrm{Zn}^{2+}: \mathrm{Se}^{2-}=2: 1$. The QD components are often used in various ratios in order to reduce the QD size dispersion. Therefore, the asymmetry between the molar concentrations of components does not lead to the QD size growth. Using DLS, we also found that the growth of the $\mathrm{Zn}^{2+}$ concentration in the solution did not result in an increase of the QD size, because the excess of $\mathrm{Zn}^{2+}$ ions becomes most likely bound with the $-\mathrm{OH}$ groups in TG. It is probable that the excess of $\mathrm{Zn}^{2+}$ ions on the QD surface gives rise to an increase of the surface charge and potential in comparison with the S11 solutions and, consequently, to the short-wave shift of the $1 S$ transition energy in those solutions by about $100 \mathrm{meV}$ as compared with the analogous transition in the S11 solutions.

The absorption bands 1 and 2 in Fig. 2 were registered for the S11 and S21 samples with a maximum molar concentration of TG, $10 \mathrm{mmol} / \mathrm{l}$. If the superficial contribution had been really depend on the number of TG molecules bound to the superficial QD atoms, then the positions of the absorption bands 1 and 2 would have been dependent on $n_{0}$ (TG). However, within the limits of experimental errors, we did not manage to reliably detect this dependence. It may be a result of the changes that the binding process of TG molecules with the superficial QD atoms undergo at $n_{0}(\mathrm{TG}) \geq 2.5 \mathrm{mmol} / \mathrm{l}$. As a result, the color of the specimens changes (see also two models for the binding of the $\mathrm{CH}_{3}$-TP ligand with CdSe QDs [24]). It is probable that this change obscures the dependence concerned.

To get rid of this factor, we fabricated solid films on the basis of the S21 solutions on quartz substrates. The thermal treatment and the film formation can reduce the number of TG molecules on the QD surface and change their internal structure. In spite of that, the absorption spectra of the films had more pronounced absorption peaks formed by $1 S$ transitions, which allowed their dependence on $n_{0}$ (TG) to be revealed. Points in Fig. 3 demonstrate the energies of $1 S$ transitions in the F2.5, F5, F7, and F10 films determined from the corresponding absorption bands at various values of the ratio $n_{0}(\mathrm{TG}) / n_{0}(\mathrm{QD})$. Only the absorption bands for the F2.5 and F10 films are shown in the inset in order not to clutter it.

Figure 3 also demonstrates the $1 S$ transition energy $E_{1 S}\left(R_{0}\right)$ and the ZnSe gap energy $E_{g 0}(\mathrm{ZnSe})$. One 


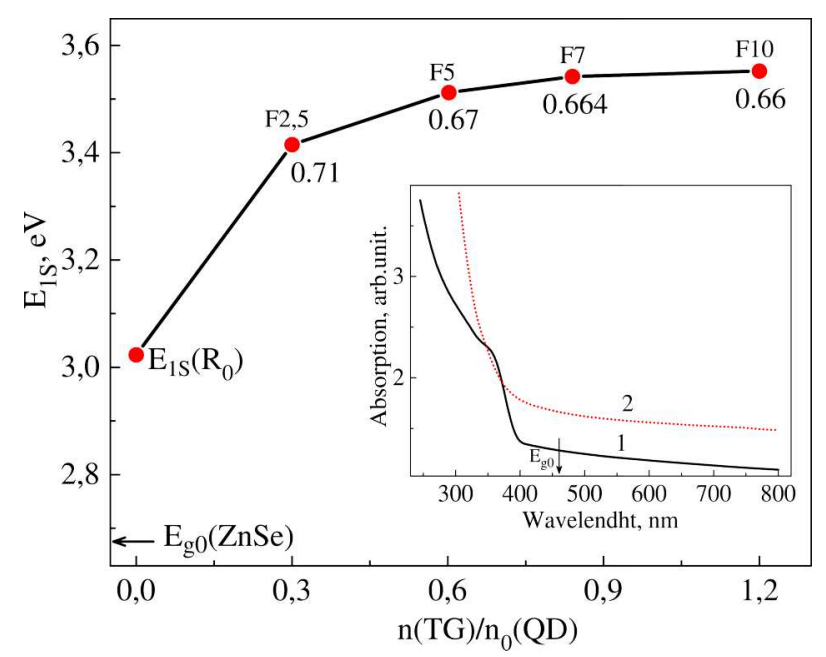

Fig. 3. Dependence of the energy of the exciton $1 S$ transition in the F2.5, F5, F7, and F10 films of the S21 specimens on the ratio $n_{0}(\mathrm{TG}) / n_{0}(\mathrm{QD})$. Numbers near the points indicate the ratio between the size of the exciton wave function and the real QD size $R_{0}$. The absorption band of the films F2.5 (1) and F10 (2) are shown in the inset

can see that the energy of the $1 S$ exciton transition in the QDs increases with the concentration of TG molecules in the solution. Since the actual size of QDs did not change in the experiment, the energy growth with the ratio $n_{0}(\mathrm{TG}) / n_{0}(\mathrm{QD})$ can be explained by the superficial contribution. The numbers near the data pointsshow the ratio between the exciton size and the real QD size, $R_{0}$. Their different values are a consequence of the electrostatic compression of the exciton wave function. Since this compression cannot be too large, the energy reaches a "plateau", as one can see in the figure. As was mentioned above, this situation is similar to that observed in spherical QDs of II-VI semiconductors with the dielectric constant $\varepsilon_{0}$ embedded into a matrix with dielectric constant $\varepsilon_{1}$ in the case where $\varepsilon_{1}<\varepsilon_{0}$. The polarization contribution to the exciton energy was approximately equal to $\left(\varepsilon_{0}-\varepsilon_{1}\right) /\left(2 R_{0} \varepsilon_{1}\right)$ and emerged owing to the dielectric mismatch and the polarization of the interfaces between the QDs and the matrix $[18,19]$. In our structures, the superficial contribution to the exciton energy should also depend not only on the number of TG molecules bound to the superficial QD atoms, but also on the dielectric constant in a near-surface layer with a thickness of about $\ell$ formed by TG around a ZnSe QD. The exciton energy is determined not only by the TG molecules that are bound to the QD sur- face, but also by those that are simply located on it without any binding. Unfortunately, the theoretical substantiation of those problems is almost absent now.

\subsection{Manifestations of exciton migration in photoluminescence spectra of $\mathrm{ZnSe} Q D$ films}

Unlike the bands in the absorption spectra of the films, the position and shape of photoluminescence bands are governed by the exciton migration and the size dispersion of ZnSe QDs. Provided the latter, the migration process can be explained, on the whole, as follows. Light-activated $e-h$ pairs in the QDs try to reduce their energy, so that they tunnel into those neighbor (nearest) QDs with a lower energy, with which the overlapping of wave functions is the largest. Tunnel jumps of excitons between such QDs are possible, if the time of their radiative recombination in QDs, $\tau_{0}$, is larger than the time of their jump into the neighbor QDs, $\tau_{h}$, i.e. if $\tau_{0}>\tau_{h}$. Tunnel jumps are governed by a number of parameters such as the exciton energy (the quantum confinement effect); the minimum distance between the surfaces of neighbor QDs, $\ell$; the height of the potential barrier created by TG; and the degree of QD dense packing in the array. The last three parameters are almost constant in a free densely packed QD array, whereas the exciton energy decreases as approximately $R^{-2}$ at every jump. When migrating, the excitons reach QDs with the radius $R_{c}$, in which $\tau_{0} \approx \tau_{h}$. Here, they are accumulated to form a peak of the photoluminescence band. The presence of QDs with this radius makes the migration of excitons and the position of their peak in the photoluminescence band independent of the excitation wavelength.

For the migration of excitons over the QD array to be efficient, it is necessary that the exciton wave functions in the neighbor QDs should substantially overlap each other. Therefore, a relative volume occupied by QDs in the films has to be not less than about $0.3[25,26]$. In our specimens, it was amounted to

$\phi=\frac{4 \pi}{3}\left(R_{0}+\ell\right)^{3} n_{0}(\mathrm{QD}) \approx 0.5$.

Assuming the spatial distribution of QDs to be random (Poisson-like), taking into account that they are not points but have finite dimensions, and using the 
results of our works $[25,26]$, we estimated the distance between the centers of the nearest ZnSe QD-TG complexes as about $6.0-6.2 \mathrm{~nm}$, which is comparable with the value of the quantity $2 R_{0}+\ell$. This correspondence of the results proves that the QDs in our films were densely packed indeed, so that the exciton migration process was efficient.

Figure 4 exhibits the photoluminescence band of the F2.5 film registered at various excitation wavelengths ranging from $\lambda_{1}$ to $\lambda_{5}$. The $1 S$ peak of this band is located at $\lambda_{1 s} \approx 403 \mathrm{~nm}$, being shifted by about $440 \mathrm{meV}$ with respect to the peak in the absorption band. A characteristic feature of this peak, as one can see from the figure, is its position that does not depend on the excitation wavelength. This fact proves the existence of QDs with $R_{c}$ in the framework of the model proposed above. Therefore, by applying the model "a particle in a spherical potential", we determined the $\mathrm{QD}$ radius corresponding to the maximum of the photoluminescence band, $R_{c} \approx 2.3 \mathrm{~nm}$, and the ratio $R_{c} / R_{0} \approx 0.8$.

Another specific feature of this peak is the growth of its intensity with the excitation wavelength from $\lambda_{1}$ to $\lambda_{5}$ (which corresponds to a reduction of the excitation energy), although the number of excited QDs decreases at that. This phenomenon can be explained by the growth of the light absorption depth in the film and the approach to the resonance, where the majority of generated excitons recombine in the $1 S$ state, as is evidenced by a drastic increase of the intensity of the photoluminescence band 5. The position of the exciton photoluminescence band in Fig. 4 is atypical exactly because $R_{c}<R_{0}$. As a rule, at their migration in densely packed arrays, excitons reach QDs with radii of about $(1 \div 2) \times R_{0}$ that are located in the tail of a distribution function (Gaussian) [27]. However, in our case, the compression of excitons reduces the overlapping degree of the wave functions between neighbor QDs to exponentially small values. The overlapping is sufficiently large only for small QDs with high kinetic energies of excitons, which are at the beginning interval of the distribution function. The migration of excitons occurs exactly between such QDs. Therefore, the intensity of the short-wave section in the photoluminescence band falls drastically, in contrast to the long-wave section, which is formed by the distribution function. This fact is another proof in favor of the proposed model concerning the

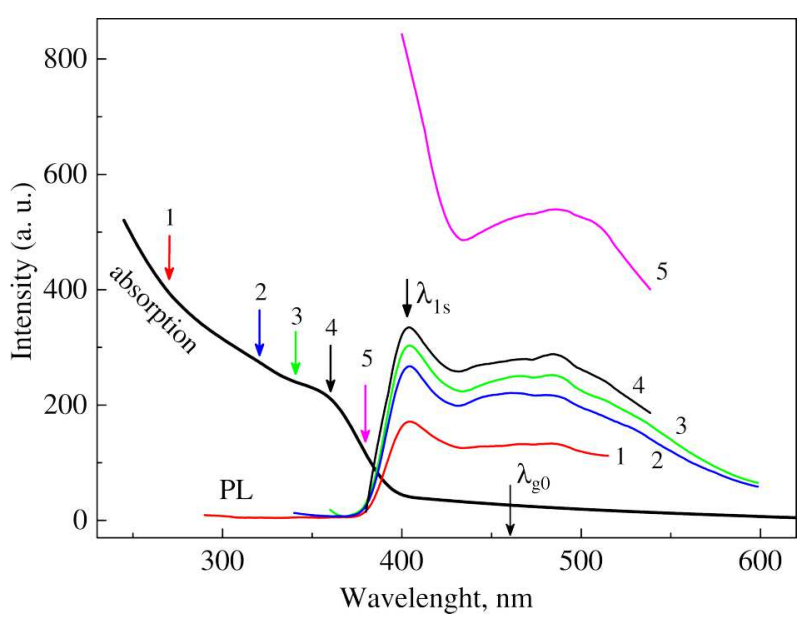

Fig. 4. Absorption and photoluminescence bands of the film F2.5 at various excitation wavelengths: 270, 320, 340, 360, and $380 \mathrm{~nm}$ (from $\lambda_{1}$ to $\lambda_{5}$ )

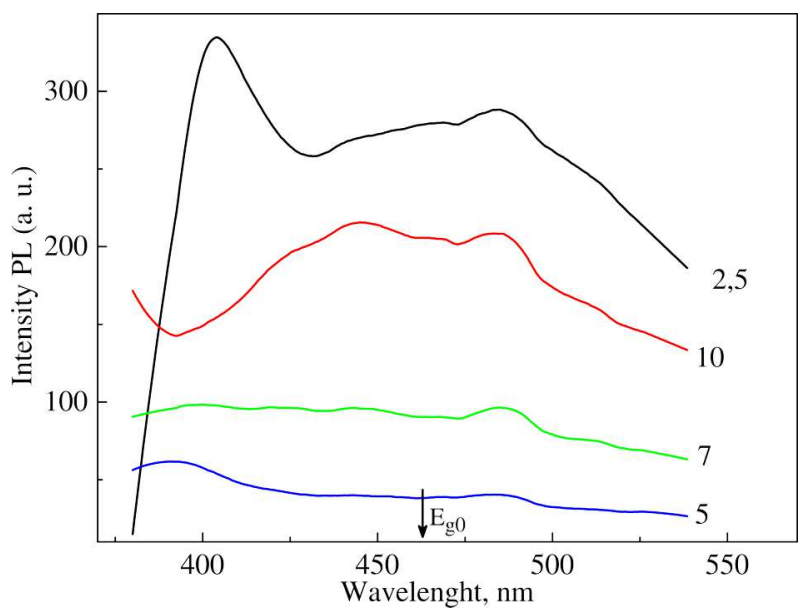

Fig. 5. Photoluminescence spectra of the films F2,5, F5, F7, and F10

electrostatic compression of the exciton wave function in QDs.

Another recombination channel forming a broad peak in the photoluminescence band with a maximum at about $\lambda_{g 0}$ is shown in Fig. 4 and is associated with excitons captured at the energy levels located in the QD band gap. These levels can arise owing to the internal defects in the QD lattice and to the states on the QD surface. The latter assumption is supported by the fact that, when the number of TG molecules on the QD surface increases, the intensity of the $1 S$ transition band in the photolumi- 
nescence spectra of the F5 films decreases by a factor of about six in comparison with the similar transition in the F2,5 films, which is shown in Fig. 5. Thus, a channel of exciton recombination through superficial defect states becomes open. The appearance of the latter leads to the change of the film color from light gray at $n_{0}(\mathrm{TG})=2.5 \mathrm{mmol} / \mathrm{l}$ to red-brown at $n_{0}(\mathrm{TG})=5 \mathrm{mmol} / \mathrm{l}$, which is a characteristic feature of the defect state formation in ZnSe-based quantum structures with various dimensions.

As the TG concentration was increased further to 7 and $10 \mathrm{mmol} / \mathrm{l}$, the number of defect states and the intensity of their photoluminescence continued to grow. It should be noted that, at the concentrations $n_{0}(\mathrm{TG}) \geq 5 \mathrm{mmol} / \mathrm{l}$, the stability of ZnSe QDs in the solution became optimal. It occurred most likely owing to the steric stabilization of QDs, which was a result of the presence of a considerable number of TG molecules on their surfaces. A relation between the optimal stability of ZnSe QD solutions with the concentrations $n_{0}(\mathrm{TG}) \geq 5 \mathrm{mmol} / \mathrm{l}$ and the formation of a significant number of defect QD states remains unclear till now. Therefore, this problem should be studied further.

\section{Conclusions}

The results obtained for the solutions and solid films of ZnSe QDs stabilized with 1-thioglycerol allowed a significant contribution (about $500 \mathrm{meV}$ ) of this stabilizer to the exciton energy to be detected for the first time, and its mechanism to be elucidated. The analysis of the solution absorption spectra showed that this contribution has an electrostatic origin and is not associated with chemically induced changes in the QD structure or the variation of the QD size during the process of QD growth. As a whole, this stabilizer action resembles the effect that was observed in IIVI semiconductor QDs in matrices with a significant dielectric mismatch. The assumption was made that this effect of TG on the exciton energy in ZnSe QDs is selective and could be absent, when using stabilizers with an anchor group different from the thiol one.

1. R.D. Harris, S.B. Homan, M. Kodaimati, Chen He, A.B. Nepomnyashchii, N.K. Swenson, S. Lian, R. Calzada, E.A. Weiss. Electronic processes within quantum dotmolecule complexes. Chem. Rev. 116, 12685 (2016).

2. N. Kholmicheva, P. Moroz, H. Eckard, G. Jensen, M. Zamkov. Energy transfer in quantum dot solids. ACS Energy Lett. 2, 154 (2017).
3. N. Hildebrandt, C.M. Spillmann, W.R. Algar, T. Pons, M.H. Stewart, E. Oh, K. Susumu, S.A. Díaz, J.B. Delehanty, I.L. Medintz. Energy transfer with semiconductor quantum dot bioconjugates: A versatile platform for biosensing, energy harvesting, and other developing applications. Chem. Rev. 117, 536 (2016).

4. M.T. Frederick, V.A. Amin, L.C. Cass, E.A. Weiss. A molecule to detect and perturb the confinement of charge carriers in quantum dots. Nano Lett. 11, 5455 (2011).

5. M.T. Frederick, V.A. Amin, N.K. Swenson, A.Y. Ho, E.A. Weiss. Control of exciton confinement in quantum dot-organic complexes through energetic alignment of interfacial orbitals. Nano Lett. 13, 287 (2013).

6. M.S. Kodaimati, Ch. Wang, C. Chapman, G.C. Schatz, E.A. Weiss. The distance-dependence of inter-particle energy transfer in the near-infrared within electrostatic assemblies of PbS quantum dots. ACS Nano 11, 5041 (2017).

7. M. Sykora, A.Y. Koposov, J.A. McGuire, R.K. Schulze, O. Tretiak, J.M. Pietryga, V.I. Klimov. Effect of air exposure on surface properties, electronic structure, and carrier relaxation in PbSe nanocrystals. ACS Nano 4, 2021 (2012).

8. S. Kundu, A. Patra. Nanoscale strategies for light harvesting. Chem. Rev. 117, 712 (2017).

9. C.S. Ponseca Jr., P. Chabera, J. Uhlig, P. Persson, V. Sundström. Ultrafast electron dynamics in solar energy conversion. Chem. Rev. 117, 10940 (2017).

10. R.D. Harris, V.A. Amin, B. Lau, E.A. Weiss. Role of interligand coupling in determining the interfacial electronic structure of colloidal CdS quantum dots. ACS Nano 10, 1395 (2016).

11. A.Ch.A. Silva, S.W. da Silva, P.C. Morais, N.O. Dantas. Shell thickness modulation in ultrasmall CdSe/ $\mathrm{CdS}_{x} \mathrm{Se}_{1-x} / \mathrm{CdS}$ core/shell quantum dots via 1-thioglycerol. ACS Nano 8, 1913 (2014).

12. Y.Q. Zhang, X.A. Cao. Optical characterization of CdSe quantum dots with metal chalcogenide ligands in solutions and solids. Appl. Phys. Lett. 99, 023106 (2011).

13. S.K. Sarkar, G. Hodes. Charge overlap interaction in quantum dot films: Time dependence and suppression by cyanide adsorption. J. Phys. Chem. B. 109, 7214 (2005).

14. Y. Nosaka, K. Yamaguchi, H. Miyama, H. Hayashi. Reversible adsorption-enhanced quantum confinement in semiconductor quantum dots. Appl. Phys. Lett. 81, 5045 (2002).

15. D.I. Kim, M.A. Islam, L. Avila, I.P. Herman. Contribution of the loss of nanocrystal ligands to interdot coupling in films of small CdSe/1-thioglycerol nanocrystals. J. Phys. Chem. B 107, 6318 (2003).

16. N.V. Bondar, M.S. Brodin, N.A. Matveevskaya. Influence of surface and polarization effects on electronic excitation energy transfer in colloidal solutions and films of $\mathrm{ZnSe}$ quantum dots. Low Temp. Phys. 44, 1532 (2018).

17. B. Goswami, S. Pal, P. Sarkar. Theoretical studies of the effect of surface passivation on structural, electronic, and optical properties of zinc selenide clusters Phys. Rev. B 76, 045323 (2007).

ISSN 2071-0194. Ukr. J. Phys. 2019. Vol. 64, No. 5 
18. Y. Nosaka. Finite depth spherical well model for excited states of ultrasmall semiconductor particles. An applicatlon. J. Phys. Chem. 95, 5054 (1991).

19. G.B. Grigoryan, A.V. Rodina, A.L. Efros. Confined excitons and biexcitons in semiconductor microcrystals embedded in an insulating glass matrix. Fiz. Tverd. Tela 32, 3512 (1990).

20. P. Schapotschnikow, B. Hommersom, T.J.H. Vlugt. Adsorption and binding of ligands to CdSe nanocrystals. J. Phys. Chem. C. 113, 12690 (2009).

21. Boon-Kin Pong, B.L. Trout, Jim-Yang Lee. Modified ligand-exchange for efficient solubilization of $\mathrm{CdSe} / \mathrm{ZnS}$ quantum dots in water: A procedure guided by computational studies. Langmuir 24, 5270 (2008).

22. S. Baskoutas, A.F. Terzis. Size-dependent band gap of colloidal quantum dots. J. Appl. Phys. 99, 013708 (2006).

23. J. Eilers, J. van Hest, A. Meijerink, C. de Mello Donega. Unravelling the size and temperature dependence of exciton lifetimes in colloidal ZnSe quantum dots. J. Phys. Chem. C. 118, 23313 (2014).

24. V.A. Amin, K.O. Aruda, B. Lau, A.M. Rasmussen, K. Edme, E.A. Weiss. Dependence of the band gap of CdSe quantum dots on the surface coverage and binding mode of an exciton-delocalizing ligand, methylthiophenolate. J. Phys. Chem. C. 119, 19423 (2005).

25. N.V. Bondar, M.S. Brodin, A.M. Brodin, N.A. Matveevskaya. Photoluminescence and confinement of excitons in disordered porous films. Semiconductors 50, 346 (2016).

26. N.V. Bondar, M.S. Brodin. Free and bound states of excitons in a percolation cluster of $\mathrm{ZnSe}$ quantum dots in a dielectric matrix. Low Temp. Phys. 37, 1026 (2011).
27. N.V. Bondar, M.S. Brodyn, N.A. Matveevskaya, T.G. Beynik. Electronic excitation energy transfer in an array of CdS quantum dots on a quasi-two-dimensional surface. Semiconductors 53, 188 (2019).

Received 15.01.19.

Translated from Ukrainian by O.I. Voitenko

М.В.Бондар, М.С. Бродин,

О.В. Твердохлібова, Н.А. Матвєєвсъка, Т.Г. Бейнік

ВПЛИВ ПОКРИВАЮЧОГО ЛІГАНДУ

НА ВЕЛИЧИНУ ЩЛИНИ ТА ЕНЕРГЕТИЧНІ

РІВНІ ЕКСИТОНІВ КОЛОЇДНИХ РОЗЧИНІВ

ТА ПЛІВОК КВАНТОВИХ ТОЧОК ZnSe

$\mathrm{P}$ е $з$ ю м е

Квантові точки напівпровідників є перспективними наноструктурами для їх використання в сонячних комірках 3го покоління, фотодетекторах, світловипромінюючих діодах та як біологічні маркери. Однак залишається відкритим питання впливу поверхневих органічних стабілізаторів (лігандів) на енергію екситонів квантових точок. На основі аналізу оптичних спектрів колоїдних розчинів та плівок квантових точок ZnSe, стабілізованих 1-тіогліцеролом, ми встановили, що енергія екситонів та їх міграція залежать не тільки від квантово-розмірного ефекту, а й поверхневого внеску за рахунок тіольної - $\mathrm{SH}$ групи стабілізатора. Вперше показана експериментальна залежність енергії екситонів у квантових точках $\mathrm{ZnSe}$ від концентрації поверхневого стабілізатора. Також показано, що короткий розмір молекулярного ланцюжка стабілізатора та велика початкова енергія екситонів, зумовлюють їх ефективну міграцію у масиві квантових точок. 